\title{
The Impacts of the Sharing Economic Model on Vietnam
}

\author{
Pham Thanh Nga, LL.M \\ Guest Lecturer, Diploma Academy of Vietnam, Vietnam \\ Email: pham.nga.hlu@gmail.com | ngapham@dav.edu.vn | Tel: +84-984-898-185
}

\begin{abstract}
In recent years, there have been many new global companies investing and operating in Vietnam as a form of sharing economy (Uber, Grab, Foody, Agoda, Facebook, Google, etc). These kinds of economic models are popular in the world but very new in Vietnam. Sharing economy enterprises bring both benefit and challenges for Vietnam. Before time, there is no policy and law to govern the activities of these companies. So they make the challenges for the authority of Vietnam to manage. This paper will analyze the nature, characters, and impacts of the sharing economy in Vietnam. It also mentions the problems and recommends some solutions to manage the activities of sharing - economy companies.
\end{abstract}

Key words: sharing economy; benefit; challenge; impactions; Vietnam; policy.

\section{Introduction}

For about five years nearly, there is an appearing of a new kind of business in Vietnam. It is known as a kind of sharing economy. This is the result of the Industrial Revolution 4.0 happening around the world. Sharing economic enterprises make business base on the applications of information technologies. Originally growing out of the open-source community to refer to peer-to-peer based sharing of access to goods and services, the term is now sometimes used in a broader sense to describe any sales transactions that are done via online market places, even ones that are business to business (B2B), rather than peer-to-peer.

In Vietnam, there are many famous international brands of sharing economy enterprises. We can call name of them as Uber, Grab, Agoda, Goolge, Facebook, Airbnb, etc. The new kind of business has made many changes of using services and goods in Vietnam. The operation of sharing economy enterprises is very different from the traditional business. The price of services is much cheaper than traditional services. So there are conflict between the sharing economy enterprises and traditional enterprises. The problem is related to the equal competition in business. Moreover, this new kind of business has created many new challenges for policy and legal makers of Vietnam as well as the administration and management of government. The government must have issued new legal documents to guiding the operation and activities of sharing economy enterprises.

Therefore, in this paper, I will analysis more detail the impacts of sharing economy enterprises activities in Vietnam. Then, I will recommendation some solutions to improve the situation. 


\section{Literature review}

\subsection{Understanding about Sharing economy}

Sharing economy is an umbrella term with a range of meanings, often used to describe economic and social activity involving online transactions. For this reason, the term sharing economy has been criticized as misleading, some arguing that even services that enable peer-to-peer exchange can be primarily profit-driven. However, many commentators assert that the term is still valid as a means of describing a generally more democratized marketplace, even when it's applied to a broader spectrum of services.

Also known as share - economy, collaborative consumption, collaborative economy or peer economy, a common academic definition of the term refers to a hybrid market model (in between owning and gift giving) of peer-to-peer exchange. Such transactions are often facilitated via community-based online services. Uberization is also an alternative name for the phenomenon.

The sharing economy may take a variety of forms, including using information technology to provide individuals with information that enables the optimization of resources through the mutualization of excess capacity in goods and services. A common premise is that when information about goods is shared (typically via an online marketplace), the value of those goods may increase for the business, for individuals, for the community and for society in general.

\subsection{Related empirical studies}

Researcher Christopher Koopman, an author of a study by George Mason University economists, said the sharing economy "allows people to take idle capital and turn them into revenue sources." He has stated, "People are taking spare bedroom[s], cars, tools they are not using and becoming their own entrepreneurs. "Run Sundararajan, a New York University economist who studies the sharing economy, told a January congressional hearing that "this transition will have a positive impact on economic growth and welfare, by stimulating new consumption, by raising productivity, and by catalyzing individual innovation and entrepreneurship".

A study in Inter-economics / The Review of European Economic Policy noted that the sharing economy has the potential to bring many benefits for the economy, while noting that this presupposes that the success of sharing economy services reflects their business models rather than 'regulatory arbitrage' from avoiding the regulation that affects traditional businesses.

An independent data study conducted by BUSBUD compared the average price of hotel rooms with the average price of Airbnb listings in thirteen major cities in the United States. The research concluded that in nine of the thirteen cities, Airbnb rates were lower than hotel rates by an average price of $\$ 34.56$. A further study conducted by BUSBUD compared the average hotel rate with the average Airbnb rate in eight major European cities. The research concluded that that the Airbnb rates were lower than the hotel rates in six of the eight cities by a factor of $\$ 72$. 
Transport. Further information: Uber (company) and Lyft. Using a personal car to transport passengers or deliveries requires payment, or sufferance, of costs for fees deducted by the dispatching company, fuel, wear and tear, depreciation, interest, taxes, as well as adequate insurance. The driver is typically not paid for driving to an area where fares might be found in the volume necessary for high earnings, or driving to the location of a pickup or returning from a drop-off point. Mobile apps have been written that help a driver be aware of and manage such costs has been introduced. Uber, Airbnb, and other companies have had drastic effects on infrastructures such a road congestion and housing. Major cities such as San Francisco and New York City have become even more congested due to ride sharing. According to transportation analyst Charles Komanoff, "Uber-caused congestion has reduced traffic speeds in downtown Manhattan by around 8 percent".

The New York Times wrote that there was a recent corporate decision by Uber which aimed at lowering its fare rates by $15 \%$ in over 100 cities in the United States. This decision caused many Uber employee drivers to assemble and express their disagreement with the recent pay cut. Uber has made a statement claiming that "when it cut prices previously, the amount of time drivers spent waiting for fares fell, meaning drivers did more business and ultimately earned more money". A number of academics recently demonstrated that in 2015 , Uber generated $\$ 6.8$ billion of consumer welfare in the United States. About local Delivery, the sharing economy model of Uber has been replicated in other similar areas. Ride sharing economy gave birth to food and grocery delivery systems. Uber launched a food-ordering app called UberEATS which not only allows users to order food, but also enables users to register to be UberEATS drivers. Similar to Uber drivers, UberEATS drivers get paid for delivering food. An example of grocery delivery in sharing economy is Instakart. It has the same business model as that of sharing economy based companies like Uber, Airbnb. Instakart uses resources that are readily available, and the shoppers shop at existing grocery shops. The contract workers use their personal vehicles to deliver groceries to customers. Instacart manages to keep its cost low as it does not require any infrastructure to store goods. In addition to having contract workers, Instacart allows signing up to be a "personal shopper" for Instacart through its official web page.

The Harvard Business Review argues that "sharing economy" is a misnomer, and that the correct word for this activity is "access economy". The authors say, "When "sharing" is market-mediated-when a company is an intermediary between consumers who don't know each other-it is no longer sharing at all. Rather, consumers are paying to access someone else's goods or services." The article goes on to show that companies (such as Uber) who understand this, and whose marketing highlights the financial benefits to participants, are successful, while companies (such as Lyft) whose marketing highlights the social benefits of the service are less successful.

The notion of "sharing economy" has often been considered as an oxymoron, and a misnomer for actual commercial exchanges. Arnould and Rose proposed to replace the misleading concept of "sharing" by that of mutuality or mutualization. A distinction can therefore be made between free mutualization such as genuine sharing and for-profit mutualization in the likes of Uber, Airbnb, or Taskrabbit. To Ritzer, this current trend towards increased consumer input in commercial exchanges refers to the notion of prosumption, which, as 
such, is not new. The mutualization of resources is for example well known in business-to-business (B2B) like heavy machinery in agriculture and forestry as well as in business-to-consumer (B2C) like self-service laundries. But three major drivers enable consumer-to-consumer $(\mathrm{C} 2 \mathrm{C})$ mutualization of resources for a broad variety of new goods and services as well as new industries. First, customer behaviour for many goods and services changes from ownership to sharing. Second, online social networks and electronic markets more easily link consumers. And third, mobile devices and electronic services make the use of shared goods and services more convenient (e.g. smartphone app instead of physical key).

Salon writes that "the sharing economy ... [is] not the Internet 'gift economy' as originally conceived, a utopia in which we all benefit from our voluntary contributions. It's something quite different-the relentless cooptation of the gift economy by market capitalism. The sharing economy, as practiced by Silicon Valley, is a betrayal of the gift economy. The potlatch has been paved over, and replaced with a digital shopping mall."

Oxford Internet Institute, Economic Geographer, Graham has argued that key parts of the sharing economy impose a new balance of power onto workers. By bringing together workers in low- and high-income countries, gig economy platforms that are not geographically-confined can bring about a 'race to the bottom' for workers.

"Unlike earlier generations of information or technology-based enterprises, sharing enterprises rely on a critical mass of providers and consumers who are sufficiently close to each other or to other amenities to make their platforms work, often finding value in the very fact of the beneficial spillovers from proximity." Uber, for example, takes people who live in one common area and transports them to another area. However, to make the initial pick up the Uber driver must be relatively close to the passenger. Urban settings inherently force people to live and work in close proximities. This means that the amount of people going to and from similar destinations is going to increase. Uber realized this and created a business format to take advantage of this new urban setting. Airbnb is another example of a company that solves a problem created by the centralized urban setting. In urban settings where there is limited space for housing people are always hard pressed to find cheaper housing and rental options when moving from city to city. AirBNB realized this and was able to take advantage of people who had space they aren't using and rent it out at cheaper costs to the people who need a place to stay for shorter amounts of time. 


\section{Methodology of research}

\subsection{Method and model}

The goodness-of-fit test in LISREL model is generally measured from overall model fit (i.e. external quality of model) and internal quality of model. In regard to overall model fit test, the common goodness-of-fit valuation indices contain (1) " $\chi 2$ ratio" (Chi-Square ratio), standing for the difference between actual theoretical model and expected value, which is better below 3, (2) goodness of fit index (GFI) and adjusted goodness of fit index (AGFI), which show better goodness-of-fit when close to 1, (3) root mean square residual (RMR), reflecting the square root of "fit residual variance/covariance mean", which is better below 0.05, and (4) incremental fit index (IFI), revealing excellent goodness-of-fit of the model when above 0.9.

The evaluation indicators for the internal quality of model in LISREL include (1) SMC (square multiple correlation) of individual manifest variables, i.e. R2 of manifest variables and latent variables, which should be above $0.5,(2)$ component reliability $(\rho)$ of latent variable, as the Cronbach's $\alpha$ of the observation indicator of the latent variable, which should be above 0.6, and (3) average variance extracted of latent variable, which is calculated by dividing the R2 sum of manifest variables in a latent variable with the number of manifest variables to reveal the percentage of the latent variable being measured with the manifest variables; the value is better above 0.5 .

\subsection{Research sample and subject}

Clients and partners of the sharing economy enterprises in Hanoi and Hochiminh city are randomly distributed 500 copies of questionnaire in this study. Total 337 valid copies are retrieved, with the retrieval rate $67 \%$. The retrieved questionnaire data are analyzed with the statistics software.

\subsection{Reliability and validity test}

Validity refers to a measurement scale being able to actually measure what a researcher intends to measure. The comm on validity contains "content validity", tending to qualitative test, "criterion validity", using known external criteria and the correlation coefficient of the test for the evaluation, and "construct validity" used for evaluating the theoretical consistency of the measurement to other observable variables. The questionnaire content in this study is based on past theories and referred to the actual conditions of the research objects to design the measuring tool, which could truly express the essence of the affair and the complete representativeness, to ensure the content validity of the questionnaire. The final commonality estimate of factor analysis is applied to test the construct validity of the measurement items, and the validity appears in $0.8 \sim 0.9$, showing good validity test result of the questionnaire. 


\section{Results and discussion}

\subsection{Impact to labor issue}

Relationship to job loss. Following the information from Vinasun, one of the big traditional taxi company in Vietnam, from when Uber and Grab appeared in Vietnam for 3 years, revenue of Vinasun has decreased $11 \%$ and profit down 35\%. They have to cut off car and staff. Therefore, many taxi driver lost job.

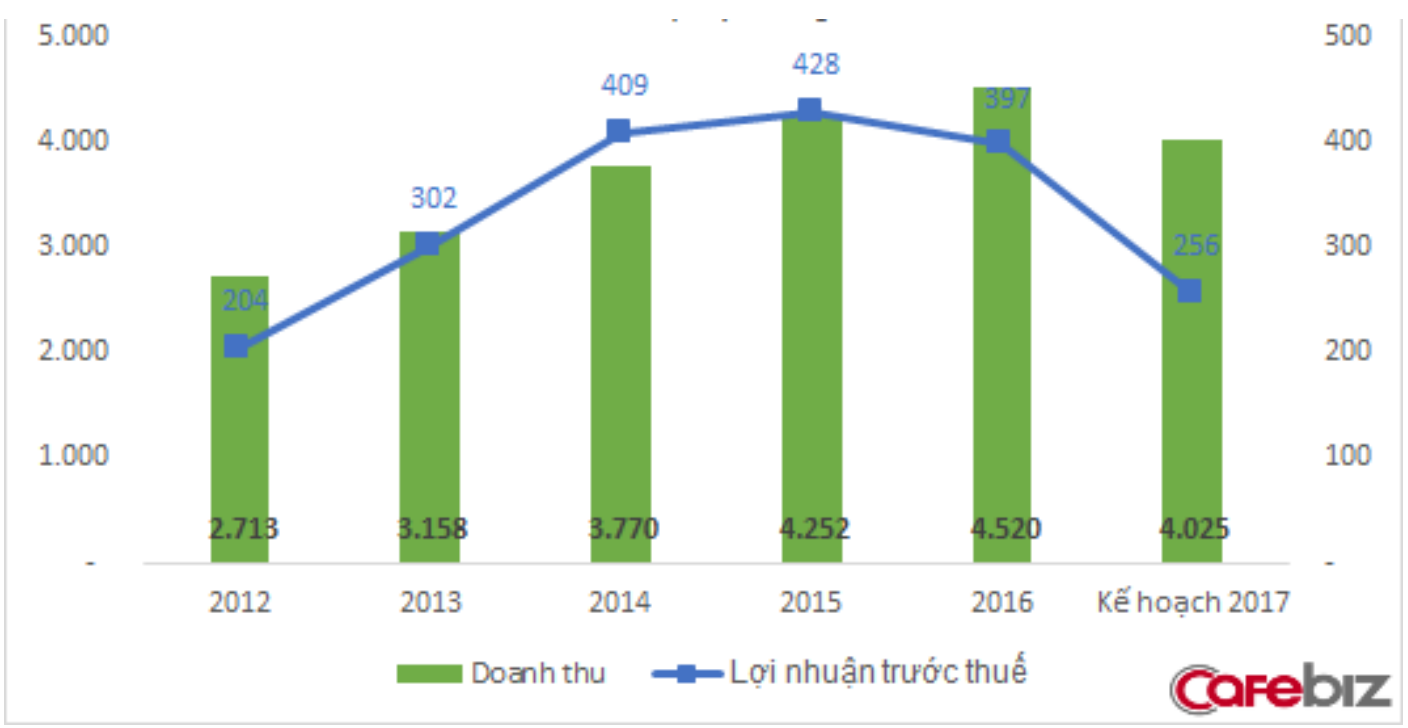

Figure 1. Vinasun Data (Unit: Billion VND)

The sharing economy has succeeded in large part because the real economy has been struggling. Specifically, in the magazine's view, the sharing economy succeeds because of a depressed labor market, in which "lots of people are trying to fill holes in their income by monetizing their stuff and their labor in creative ways," and that in many cases, people join the sharing economy because they've recently lost a full-time job, including a few cases where the pricing structure of the sharing economy may have made their old jobs less profitable (e.g. full-time taxi drivers who may have switched to Uber or Grab). The magazine writes that "In almost every case, what compels people to open up their homes and cars to complete strangers is money, not trust. ... Tools that help people trust in the kindness of strangers might be pushing hesitant sharing-economy participants over the threshold to adoption. But what's getting them to the threshold in the first place is a damaged economy, and harmful public policy that has forced millions of people to look to odd jobs for sustenance.

Some people believe the recent recession lead to the expansion of the sharing economy because people could easily employ themselves through the services that these companies offer. However, this concept is only hiding the fact that such employment is only a new face for contractual work and temporary employment that doesn't provide the necessary safeguards for modern living. When companies use contract based employment, the "advantage for a business of using such non-regular workers is obvious: It can lower labor costs dramatically, often by 30 percent, since it is not responsible for health benefits, social security, 
unemployment or injured workers' compensation, paid sick or vacation leave and more. Contract workers, who are barred from forming unions and have no grievance procedure, can be dismissed without notice".

Circumventing labor protection law(s)

Economy wrote about the debate over the status of the workers within the sharing economy, whether they should be treated as contract workers or employees of the companies. This issue seems to be most relevant among sharing economy companies such as Uber. The reason this has become such a big issue is that the two types of workers are treated very differently. Contract workers are not guaranteed any benefits and pay can be below average. However, if they are employees, they are granted access to benefits and pay is generally higher. The State of California is trying to go after Uber and make them pay a fine to compensate workers fairly. The California Public Utilities Commission was working on a case that "addresses the same underlying issue seen in the contract worker controversy-whether the new ways of operating in the sharing economy model should be subject to the same regulations governing traditional businesses". Like Uber, Instakart too had to face similar lawsuits. In 2015, a lawsuit was filed against Instakart alleging the company misclassified a person who buys and delivers groceries as independent contractor. [100] Instakart had to eventually make all such people as part-time employees and had to accord benefits such as health insurance to those qualifying. This lead to Instakart having thousands of employees overnight from zero. Benefits not accrued evenly.

Susie Cagle wrote that the benefits big sharing economy players might be making for themselves are "not exactly" trickling down, and that the sharing economy "doesn't build trust" because where it builds new connections, it often "replicates old patterns of privileged access for some, and denial for others." William Alden wrote that "The so-called sharing economy is supposed to offer a new kind of capitalism, one where regular folks, enabled by efficient online platforms, can turn their fallow assets into cash machines ... But the reality is that these markets also tend to attract a class of well-heeled professional operators, who outperform the amateurs-just like the rest of the economy."

The local economic benefit of the sharing economy is offset by its current form, which is that huge tech companies reap a great deal of the profit in many cases. For example, Uber, which is estimated to be worth $\$ 50 \mathrm{~B}$ as of mid-2015, takes up to $30 \%$ commission from the gross revenue of its drivers, leaving many drivers making less than minimum wage.

\subsection{Impact to tax and legal policy}

The appearance of sharing economy enterprises made a new challenge for Vietnamese Government. Sharing economy is very new and the legal system of Vietnam lack of the provisions to govern activities of these company. The law makers have to update and enact new policy and regulations to govern the activities of sharing economy enterprise. For more detail as following:

To manage the activities of sharing economy enterprises, the authority has discussed and combat so much to decide to admit this kind of economy in Vietnam. The government has permitted these company operate 
legally in Vietnam and require them obligate regulations of Vietnam. When some traditional company disagree with new company of sharing economy because they think sharing economy will kill the traditional business, the government had to recommend to legal maker and policy make new law and change regulation to govern the sharing economy. For example, to collect tax of sharing economy enterprises such as Uber, Grab or Facebook, the ministry of finance must give new accounting tax of enterprise income and individual income tax as well as VAT. This regulation to make the equal competition between the traditional business and sharing - economy company. Vietnamese authority is continuing to improve the regulations to manage the sharing economy enterprises better.

Besides the change of tax policy, Vietnam's Government also recommend the Parliament amendment Article 292 Code of Criminal 2015. When new Panel Code is enacted, the start-up community was very worry because of new provision of Article 292. They feel that regulation will prison all of founder of IT startup. Article 292 has some regulation criminalization some business activities (trade). Therefore, the startup community require the law maker remove the 292 out of the Penal Code 2015. Before the anti-Article 292 very hard, the government had to recommend the Parliament amend the Penal code 2015 although it is just enacted. And this situation make a new trend and impact directly to process of law making in Vietnam. It create the democratic regime in law making. I think this is a good and positive impaction of sharing economy bring to Vietnam.

\subsection{Impact to environment}

Reducing negative environmental impact by reducing the amount of good needing to be produced which cuts down on industry pollution (such as reducing the carbon footprint and consumption of resources). In sharing economy, we can share many things such as car, house. When we use one thing together, the cost is reduce. Moreover, it help reduce the use of material such as oil, gas, paper, electric ... Therefore it reduce the CO2 and dust, economy the water, traffic jam, ... Of course, the pollution of air and water will reduce and improve the quality of environment. So we can conclude that sharing economy impact well and positive to the environment.

\subsection{Impact to the price and quality of services}

Saving costs by borrowing and recycling items. Providing people with access to goods who can't afford buying them or have no interest in long-term usage. In Vietnam, the taxi price before very high until Uber and Grab appear. The service price of Uber and Grab is cheaper than traditional taxi but the quality is still better. This is why many people in Vietnam have change the habit use Uber and Grad service instead of traditional taxi like Vinasun taxi or Mailinh taxi. The impaction of price on taxi service is very positive. It require the traditional taxi company must be improve the quality and reduce the price. It is very good for clients and protect the client better because they will have more choice to use the service. In general, the competitiveness of price between the sharing economy enterprise and traditional company is good to develop the economy positively.

\subsection{Others issues}


Business Insider wrote that companies such as Airbnb and Uber do not share their reputation data with the very users who it belongs to. This is an issue since no matter how well you behave on any one platform, your reputation doesn't travel with you. This fragmentation has some negative consequences, such as the Airbnb squatters who had previously deceived Kickstarter users to the tune of $\$ 40,000$. Sharing data between these platforms could have prevented the repeat incident. Business Insider's view is that since the Sharing Economy is in its infancy, this has been accepted.

However, as the industry matures, this will need to change. Giana Eckhardt and Fleura Bardhi say that the sharing economy promotes and prioritizes cheap fares and low costs rather than personal relationships, which is tied to similar issues in crowdsourcing. For example, Zipcar is advertised as a ride-sharing service, but it's been brought into consideration that the consumers reap similar benefits from Zipcar as they would from, say, a hotel. In this example, there is minimal social interaction going on and the primary concern is the low cost. Other examples many include myriad other sharing economies such as AirBnB or Uber. Because of this, the "sharing economy" may not be about sharing but rather about access. Giana Eckhardt and Fleura Bardhi say the "sharing" economy has taught people to prioritize cheap and easy access over interpersonal communication, and the value of going the extra mile for those interactions has diminished.

\section{Conclusions and recommendation}

The results show that participation in sharing economy is motivated by many factors such as its sustainability, enjoyment of the activity as well as economic gains. The "sharing economy" may not be about sharing but rather about access. Giana Eckhardt and Fleura Bardhi say the "sharing" economy has taught people to prioritize cheap and easy access over interpersonal communication, and the value of going the extra mile for those interactions has diminished.

In Vietnam, sharing economy bring many new valuation and make many new impaction to the people and social. It not only make benefit to the economy and clients but also challenge to the authority how to manage sharing economy enterprises. It help to boost the government and Parliament of Vietnam improve the legal system to cover and govern new kind of economy.

When the sharing economy just appear in Vietnam, the authority is confused and passive to manage. Then, they must research about sharing economy and find out some new policy to manage. The lesson is the Vietnam's leaders need to more active to enact the policy and law that have prediction and vision with the changing economy. If the Vietnam's authority have a good prediction and vision, they will avoid passive and more active to manage the sharing economy and other issue in social. 


\section{REFERENCES}

1. Harvard Business Essentials (2006), Performance Management

2. www.wikipedia.org

3. http://vietnamnet.vn/vn/goc-nhin-thang/tin-moi-ve-thue-cua-uber-facebook-google-nop-cho-viet-namtu-goc-nhin-thang-357337.html

4. www.uber.com

5. www.chinhphu.vn

6. http://genk.vn/vinasun-dang-chiu-ap-luc-qua-lon-tu-uber-grab-phai-cat-giam-300-xe-taxi-tu-dat-muc-tieuloi-nhuan-giam-toi-35-20170417161411608.chn 
APPENDIX. LIST OF SHARING ECONOMY MODEL

\begin{tabular}{|c|c|c|}
\hline Bank & Property & Other \\
\hline Peer-to-peer banking & Bartering & Club theory \\
\hline Peer-to-peer lending & Book swapping & Wikimedia \\
\hline \multirow[t]{2}{*}{ Virtual currency } & Borrowing center & Wikipedia \\
\hline & Clothes swapping & See also[edit] \\
\hline Labor & Fractional ownership & Co-creation \\
\hline Coworking & Freecycling & Collaborative finance \\
\hline \multirow[t]{4}{*}{ Freelance marketplace } & Free store & Collaborative innovation network \\
\hline & Peer-to-peer renting & Cooperative \\
\hline & List of tool-lending libraries & Creative Commons \\
\hline & Toy library & Digital collaboration \\
\hline Food & Transportation & Internet of things \\
\hline Cafeteria & Bike sharing system & Internet of Services \\
\hline Food bank & Carpool & Online platforms for collaborative \\
\hline Social dining & Carsharing and peer-to-peer & consumption \\
\hline \multirow[t]{6}{*}{ Travel } & carsharing & Open Knowledge Foundation \\
\hline & Cycling & Open source \\
\hline & Real-time ridesharing & P2P Foundation \\
\hline & Share taxi & Peer-to-peer (meme) \\
\hline & Share parking space & Recommerce \\
\hline & Transportation network company & Reputation capital \\
\hline Real estate & Technology & Reputation systems \\
\hline Airbnb & Cloud computing & Secondhand good \\
\hline Co-housing & GNU Project & Social collaboration \\
\hline Coliving & Open-source software & Social commerce \\
\hline Collaborative workspace & Volunteer computing & Social peer-to-peer processes \\
\hline Couchsurfing & Digital rights & \\
\hline Emergencybnb & & \\
\hline Home exchange & & \\
\hline Peer-to-peer property rental & & \\
\hline
\end{tabular}

